\title{
A molecular dynamics simulation study of the ACE2 receptor with screened natural inhibitors to identify novel drug candidate against COVID-19
}

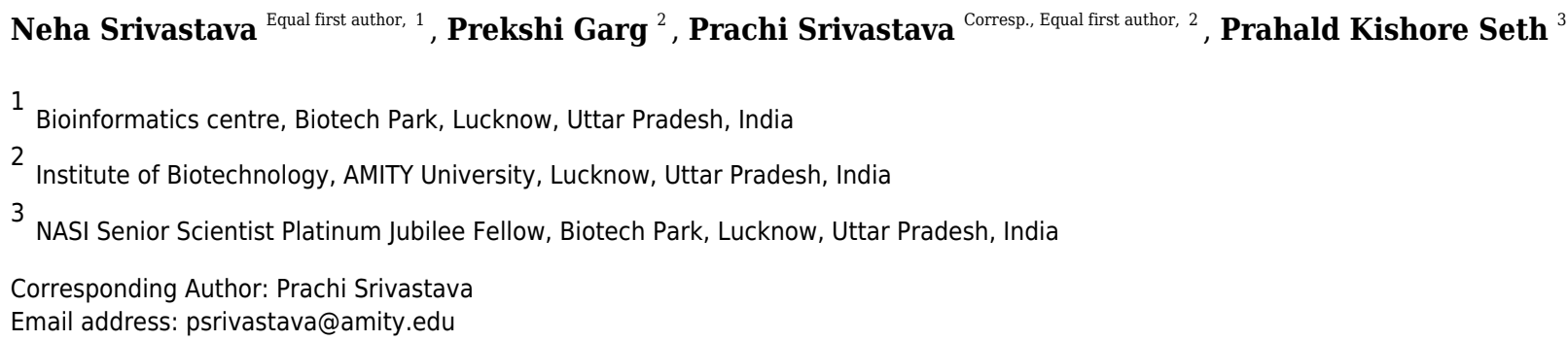

Background \& objectives: The massive outbreak of Novel Severe Acute Respiratory Syndrome Coronavirus (SARS-CoV-2) has turned out to be a serious global health issue worldwide. Currently, no drugs or vaccines are available for the treatment of COVID-19. The current computational study was attempted to identify a novel therapeutic inhibitor against novel SARS-CoV-2 using insilico drug discovery pipeline. Methods: In the present study, the human Angiotensin-converting enzyme 2 (ACE2) receptor was the target for the designing of drugs against the deadly virus. The 3D structure of the receptor was modeled $\&$ validated using Swiss-model, Procheck \& Errat server. A molecular docking study was performed between a group of natural $\&$ synthetic compounds having proven anti-viral activity with ACE2 receptor using Autodock tool 1.5.6. The molecular dynamics simulation study was performed using Desmond $v 12$ to evaluate the stability and interaction of the ACE2 receptor with a ligand. Results: Based on the lowest binding energy, confirmation, and $\mathrm{H}$-bond interaction, cinnamic acid $(-5.20 \mathrm{kcal} / \mathrm{mol})$, thymoquinone $(-4.71 \mathrm{kcal} / \mathrm{mol})$, and andrographolide (Kalmegh) $(-4.00 \mathrm{kcal} / \mathrm{mol})$ were screened out showing strong binding affinity to the active site of ACE2 receptor. MD simulations suggest that cinnamic acid, thymoquinone, and andrographolide (Kalmegh) could efficiently activate the biological pathway without changing the conformation in the binding site of the ACE2 receptor. The bioactivity and drug-likeness properties of compounds show their better pharmacological property and safer to use. Interpretation $\boldsymbol{\&}$ Conclusions: The study concludes the high potential of cinnamic acid, thymoquinone, and andrographolide against the SARS-CoV-2 ACE2 receptor protein. Thus, the molecular docking and MD simulation study will aid in understanding the molecular interaction between ligand and receptor binding site, thereby leading to novel therapeutic intervention. Keywords: SARS-CoV-2, ACE2 receptor, Natural compounds, Molecular Docking, Molecular Dynamics Simulation, Drug Discovery. 


\title{
Molecular Dynamics Simulation Study of ACE2 Receptor with Screened Natural Inhibitors to Identify Novel Drug Candidate against COVID-19
}

\begin{abstract}
\end{abstract}

\section{Background \& objectives:}

The massive outbreak of Novel Severe Acute Respiratory Syndrome Coronavirus (SARS-CoV2) has turned out to be a serious global health issue worldwide. Currently, no drugs or vaccines are available for the treatment of COVID-19. The current computational study was attempted to identify a novel therapeutic inhibitor against novel SARS-CoV-2 using an insilico drug discovery pipeline.

\section{Methods:}

In the present study, the human Angiotensin-converting enzyme 2 (ACE2) receptor was the target for the designing of drugs against the deadly virus. The 3D structure of the receptor was modeled \& validated using Swiss-model, Procheck \& Errat server. A molecular docking study was performed between a group of natural \& synthetic compounds having proven anti-viral activity with ACE2 receptor using Autodock tool 1.5.6. The molecular dynamics simulation study was performed using Desmond $v 12$ to evaluate the stability and interaction of the ACE2 receptor with a ligand.

\section{Results:}

Based on the lowest binding energy, confirmation, and H-bond interaction, cinnamic acid (- 5.20 $\mathrm{kcal} / \mathrm{mol})$, thymoquinone $(-4.71 \mathrm{kcal} / \mathrm{mol})$, and andrographolide (Kalmegh) $(-4.00 \mathrm{kcal} / \mathrm{mol})$ were screened out showing strong binding affinity to the active site of ACE2 receptor. MD simulations suggest that cinnamic acid, thymoquinone, and andrographolide (Kalmegh) could efficiently activate the biological pathway without changing the conformation in the binding site of the ACE2 receptor. The bioactivity and drug-likeness properties of compounds show their better pharmacological property and safer to use.

\section{Interpretation \& Conclusions:}

The study concludes the high potential of cinnamic acid, thymoquinone, and andrographolide against the SARS-CoV-2 ACE2 receptor protein. Thus, the molecular docking and MD simulation study will aid in understanding the molecular interaction between ligand and receptor binding site, thereby leading to novel therapeutic intervention.

Keywords: SARS-CoV-2, ACE2 receptor, Natural compounds, Molecular Docking, Molecular Dynamics Simulation, Drug Discovery. 


\section{Introduction}

Novel Severe Acute Respiratory Syndrome Coronavirus (SARS-CoV-2) is a unique virus with an unusually large positive-sense RNA genome ranging from o $32 \mathrm{~kb}$ in length [1] and a special replication strategy. It is a member of the largest group of viruses, Nidovirales [2]. It is enveloped and characterized by club-like spikes that project out from the surface. The receptorbinding domain of spike protein binds with the host cell and makes the virus capable of causing a variety of diseases in the host [3]. It causes enteritis in cows and pigs and upper respiratory disease in birds. It is now proven to cause potentially lethal respiratory infections in humans. Before the outburst of the coronavirus, it was thought that these viruses cause only mild, respiratory infections in humans but after the outburst, lethal side effects of the virus have become the major global concern. These viruses are known to cause more severe diseases in neonates, the elderly, and individuals with underlying illnesses [4].

In December 2019, Wuhan, China became the center of the outburst of the novel SARS-CoV-2 virus which raised intense and urgent concern internationally. A similar outburst of the SARS$\mathrm{CoV}$ virus was also experienced in 2003 in Guangdong, China. The number of cases at that time increased substantially and spread globally [5]. In 2003, the virus-infected approximately 8000 people and caused 774 deaths worldwide [6]. The major reason for the spread of SARS-CoV in 2003 was the ability of the virus to transmit rapidly among people. Also, the insufficient preparedness and implementation of control measures lead to the further spread of the virus. Learning from the past experiences, isolation of people suspected to have the disease, close monitoring of their contacts, epidemiological and clinical data collection from patients, and development of diagnostic as well as treatment procedures are some of the widely accepted measures adopted to control the spread of novel coronavirus [7]. The 2019 outbreak of novel SARS-CoV-2 has infected more than $66,818,411$ people with $1,428,870$ deaths worldwide as of November 2020. The control of the spread of the virus and also an adequate plan of action and treatment of the virus is the major need of the hour. Therefore, researchers are now trying to find a drug that can considerably treat the effects of the virus. In the present study, we aim to identify compounds that can be used as prophylactics against novel SARS-CoV-2. Coronavirus contains a genome of approximately $30 \mathrm{~kb}$ and consists of a 5 ' cap structure and 3 ' poly(A) tail that allows it to act as mRNA for the translation of the replicase polyproteins. At the beginning of each structural or accessory gene, there is the presence of transcriptional regulatory sequences (TRSs) which are essential for the expression of each of these genes. SARS-CoV-2 is known to bind with angiotensin-converting enzyme 2 (ACE2) as its receptor to gain entry into the human cells [8]. Various non-structural proteins assemble into the replicase- transcriptase complex of the viral genome to provide an environment suitable for the synthesis of RNA and also contain enzyme domains and functions which are important for the replication of RNA. Various nonstructural proteins (nsp) play an important role in spreading and activating the virus inside the host. Nsp1 promotes cellular mRNA degradation and blocks host cell translation, which ultimately results in the blockage of the innate immune response $[9,10]$. Nsp2 binds to 
prohibition proteins and further enhances the spread of the virus in the body [11]. Nsp3 is a large, multi-domain transmembrane protein consisting of Ubll and Ac domains that interact with $\mathrm{N}$ protein, ADRP activity that promotes cytokine expression, and PLPro/ Deubiquitinase domain that cleaves viral polyprotein and blocks host innate immune response [12-14]. Nsp4 and nsp6 are potential transmembrane scaffold proteins, important for the proper structure of DMVs $[15,16]$. Nsp5 cleaves viral proteins, nsp7, and nsp8 act as a clamp for RNA polymerase [17] nsp9 is an RNA binding protein, and nsp13 acts as RNA helicase for the viral genome. Nsp10 acts as a cofactor for nsp14 (an important protein for proofreading of the viral genome [18]) and nsp16 (shields viral RNA from MDA5 recognition [19]) and stimulates ExoN and 2-0-MT activity $[20,21]$.

Novel SARS-CoV-2 is very similar to SARS-CoV [22-24]. Both these viruses belong to the betacoronavirus genus (lineage B) $[25,26]$. The detailed comparison of SARS-CoV, MERS-CoV, and SARS-CoV-2 is depicted in table 1 [27].

The entry of the virus into the cell is one of the most primary and essential steps for the spread of disease caused by novel SARS-CoV-2. This virus encodes a surface glycoprotein known as spike [28]. The receptor-binding domain (RBD) of the spike protein is responsible for binding with the host cell receptor and mediates the entry of the virus into the cell. The virus enters the host cell due to the release of spike fusion peptide formed as a result of cleavage of spike protein by the host protease $[29,30]$. The similarity in the receptor-binding domain of both SARS-CoV-2, suggests that both these viruses share a common receptor, ACE2. Angiotensin-converting enzyme 2 (ACE2) is primarily found in alveolar epithelial cells [31] and is responsible for reducing the surface tension of these cells, thereby preventing the collapse of alveoli. Therefore, ACE2 is a very important protein to ensure proper gas exchange through the lungs. Any injury caused in such cells will lead to severe lung injury, which was commonly observed in COVID19 patients. The binding of the spike protein of SARS-CoV-2 with ACE2 of host cell leads to endocytosis of virus and loss of ACE2 function, therefore due to this binding, the cell loses its main component which was responsible for protecting the lungs from any injury. This makes the host vulnerable to viral infection. The receptor-binding domain of the spike glycoprotein binds to the tip of subdomain 1 of ACE2. The viral membrane fuses with the host cell and activates the cell [32-34]. After fusion, viral RNA is released into the cytoplasm that establishes infection. Thus, targeting the ACE2 receptor of host cells can block the entry of the virus into the cell, thereby protecting the host from viral infection and pandemic disease COVID-19.

Ever since the outburst of the pandemic, researches are going on worldwide, to explore different aspects of SARS-CoV-2 and the mechanism of infection. From repurposing drugs to finding new drugs and vaccine candidates, the studies on SARS-CoV-2 have come a long way. Some of the recent studies explore new immunogenic dimensions of the pandemic. In one of the studies, the researchers took the ontological approach to identify targets, both in the virus and the host, that can aid in searching for effective vaccines and drugs against COVID-19 [35]. In another study, researchers conducted molecular modeling intending to reveal new druggable binding sites in the 
115

116

117

118

119

120

121

122

123

124

125

126

127

128

129

130

131

132

133

134

135

136

137

138

139

140

141

142

143

144

145

146

147

148

149

150

spike protein of SARS-CoV-2. In their study, they disclosed 8 novel druggable binding sites of spike protein [36]. In one of the studies, the scientists tested the potential of flavonols to act as antiviral drugs by targeting spike protein, SARS-CoV-2 proteases, RNA-dependent RNA polymerase, and ACE2 receptor [37].

Therefore, there is a need for more effective and rational approaches that open the door to the development of more effective new therapeutics targets and drug candidates against Covid-19. In this regard, computational approaches play a significant role in the process of rapid drug discovery and development process with less time and cost-effective manner. Besides this, herbal medication shows a hugely significant impact on human health [38]. Nearly about $70-80 \%$ of the world population relies on herbal drugs due to their great compatibility with lower/zero sideeffects on human health. The bio-active constituents present in the plants possess medicinal properties is used by various pharmaceutical and R \& D industries for the development of drug due to their safer and better use [39]. In the current insilco study, drug discovery approaches are implemented to identify novel therapeutic inhibitors against novel SARS-CoV-2 targeting the human Angiotensin-converting enzyme 2 (ACE2) receptor.

\section{Methodology}

\subsection{Protein Structure Prediction and Validation}

The protein sequence of the ACE2 receptor was retrieved in FASTA format from the NCBI public database. For the identification of similar sequences, the BLAST program was performed for the search of structurally similar sequences with a protein databank database (PDB) [40]. The 3D structure of the ACE2 receptor was modeled using online modeling server SWISS-Model [41] based on the BLAST parameter. Further, the energy minimization of the modeled structure was done using Chimera 1.10.1 tool [42]. The 3D structure was subjected to validation using Procheck and Errat Plot. The Ramachandran plot [43] evaluates any steric clashes and structure reliability whereas the errat plot measures the overall error frequency rate in modeled structure.

\subsection{Ligand Identification}

The Thirty natural \& synthetic compounds having proven in-vitro \& in-vivo anti-viral activity was used in the study based on various literature reviews are depicted in table $2 \&$ table 3 [44]. The available 2D \& 3D structures of compounds were retrieved from the PubChem database. Molinspiration chemoinformatics software was used to predict the Molecular and bioactivity analysis as well as drug-likeness properties of these compounds.

\subsection{Molecular Docking Study}

A molecular docking study was performed between the ACE2 receptor and 30 natural \& synthetic compounds using the Autodock 1.5.6 tool to predict the best binding score, affinity, and confirmation $[45,46]$. AutoDock is an automated suite of protein-ligand docking tools used 
151 to predict the protein interactions with small molecules such as drug molecules and substrate. It 152 analyzes the interaction of ligand molecules at the specified target site of the protein. AutoDock 153 uses AMBER forcefield and linear regression to predict the free binding energies [47]. The 154 lowest binding energy was the criteria undertaken to select the best protein-ligand complex. 155 Calculation of binding energy was performed using a semi-empirical free energy force field with 156 charge-based desolvation and grid-based docking. The force field was selected based on a 157 comprehensive thermodynamic model that allows the incorporation of intermolecular energies 158 into the predicted binding energy [48]. Cygwin platform was used to run docking files. 159 Discovery Studio 4.5 was used to visualize and analyze protein-ligand interaction and 160

The molecular dynamic simulation study was performed to examine the conformational changes in the protein that occurred due to the ligand-binding site and to evaluate the effect of these changes over the protein-ligand complex $[49,50]$. To evaluate the stability and interaction of the ACE2 receptor with ligand simulation study was performed using Desmond $v 12$ Schrödinger software package at $50 \mathrm{~ns}$ time period [51]. The complex was placed in protein preparation wizard for optimization, analysis, and refinement of docking complex, system builder menu set up membrane model POPC (Palmitoyl Oleoyl Phasphatidyl chlorine). Water molecules were added to the docking complex of the ACE2 receptor with a simple point charge (SPC) water model. System builder was build using counter ions, shake algorithm used to constrain the geometry of water molecules, and heavy atom bond lengths with hydrogen, electrostatic interaction applied using Particle Mesh Ewald (PME) method and Orthorhombic were used as periodic boundary conditions (PBC). The energy was minimized with 5000 steps maximum iteration using the steepest descent algorithm (SD) and 1000 steps using the conjugate- gradient algorithm (CG) with convergence threshold 50 e. Dynamic was performed with $50 \mathrm{~ns}$, during the simulation the length of bond involving hydrogen was constrained using NPT ensemble, without restraints, for a simulation time of 1.2 picoseconds (ps) (temperature 300K) was performed to relax the system.

\section{Result}

\subsection{D Structure Prediction \& Validation}

The total length of the ACE2 receptor in humans is 805 amino acids. The 3D model of protein was modeled using the online modeling server SWISS-Model. Based on the lowest z-score and valid q-mean score the best model was predicted. The modeled 3D structure was subjected to validation using Procheck and Errat Plot. The Ramachandran plot was used to evaluate the position of amino acid residues in the allowed and disallowed region and the overall stereochemical property of the protein structure. Errat plot was used to calculate the overall error frequency rate. The Ramachandran plot showing $90.9 \%$ in the favored region; indicate good structure stability and reliability. The errat plot showing quality factor $96.08 \%$ reveals non- 
189 bonded interaction with different atoms in the modeled structure which indicates good quality of 190 the model (Fig1).

\section{3.2. Molecular Docking Study}

192 Molecular docking study is known to be the most reliable method to analyze and predict the best

193

194

195

196

197

198

199

200

201

202

203

204

205

206

207

208

209

210

211

212

213

214

215

216

217

218

219

220

221

222

223

224

225

226 fit protein-ligand confirmation [52, 53]. A molecular docking study was performed between ACE2 receptor and thirty compounds using Autodock 1.5.6 tools to obtain a higher stable protein-ligand complex (Table4). Based on the lowest binding energy $\left(\Delta \mathrm{G}_{\mathrm{b}}, \mathrm{kcal} / \mathrm{Mol}\right)$, confirmation, hydrogen bond interaction, the three compounds namely Cinnamic acid(-5.20 $\mathrm{kcal} / \mathrm{mol})$, Thymoquinone(-4.71 kcal/mol), and Andrographolide(Kalmegh) $(-4.00 \mathrm{kcal} / \mathrm{mol})$ were screened out showing strong binding affinity to the active site of ACE2 receptor (Fig2 \& Table 5). Thus these compounds may be considered as a suitable therapeutic inhibitor against SARS-CoV-2. Further, all three dock complexes were subjected to a molecular dynamics simulation study to check the stability of protein-ligand complexes.

\subsection{Molecular Dynamic Simulation study}

MD simulation study was performed to check the stability of the ACE2 receptor with cinnamic acid, thymoquinone, and green chireta using Desmond $v 12$ based on docking results and h-bond interaction study. To study the stabilities, root means square deviation (RMSD) was calculated with respect to the initial structures along the $50 \mathrm{~ns}$ (ns) each trajectory with average RMSD (Root mean square deviation) 12.0A - 4.5A for ACE2-cinnamic acid complex (Fig.3), 12.0A 6.0A for ACE2-thymoquinone complex (Fig.4), and 12.0A - 6.0A for ACE2Andrographolide(Kalmegh) (Fig5). In summation, complex stability also proved the validity of the docking results. There is no effect of temperature and pressure on the conformation of the structure.

\section{Discussion \& Conclusion}

The causative agent of COVID-19 respiratory disease, novel coronavirus SARS-CoV-2 pandemics is occurring as a life-threatening disease infecting more than 66,818,411 people worldwide. Nearly about $1,428,870$, total deaths estimated so far. At current, there are no available antiviral drugs or vaccines with proven efficacy for the prevention and treatment of the diseases. Therefore, a more effective and rational approach is needed that will ultimately lead to new therapeutic approaches. In this regard, the computational approach holds promising trends in the drug discovery \& development process with reducing cost and time. In the current insilico study, the angiotensin-converting enzyme 2 (ACE2) receptor was taken as the target protein as various literature studies suggested that ACE2 as a functional SARS-CoV-2 receptor required for host cell entry and subsequent viral replication [54]. The 3D structure of the ACE2 receptor was modeled and validated. A docking study of filtered natural \& synthetic compounds was performed with the ACE2 receptor. Based on the lowest binding energy, docking confirmation, and H-bond and pi-pi interaction Cinnamic acid $(-5.20 \mathrm{kcal} / \mathrm{mol})$, Thymoquinone (-4.71 $\mathrm{kcal} / \mathrm{mol})$, and Andrographolide (Kalmegh) $(-4.00 \mathrm{kcal} / \mathrm{mol})$ showing strong binding at the active 
227 site of ACE2 receptor. Further, The MD simulation result reveals that cinnamic acid,

228

229

230

231

232

233

234

235

236

237

238

239

240

241

242

243

244

245

246

247

248

249

250

251

252

253

254

255

256

257

258

259

260

261

262

263

264

265

266 thymoquinone, and andrographolide could efficiently activate the biological pathway without changing the conformation in the binding site of the ACE2 receptor. The bioactivity and druglikeness properties of compounds show their better pharmacological property and safe to use.

Cinnamic acid derived from the plant Bromeliad, have a virucidal activity, involved in the inhibition of the viral replication cycle including the formation of the viral envelope and cell membrane thereby affecting the whole epidemiology of the viral protein. It is known to be an excellent phytochemical that have cytopathic activities against all viral infections. The study reported [55] the potential of plant extracts and natural compounds against SARs CoV-2 and other deadly viruses showed the suppressive effect of trans-cinnamic acid (IC50=3.0 \pm 0.18 $\mu \mathrm{g} / \mathrm{ml}, \mathrm{SI}=7.4$ ) on Covid-19 infection. The molecular docking study conducted on Vero cell against SARS CoV-2 viral infection targeting Mpro protein showed the highest activity with cinnamic acid [56]. Thymoquinone derived from the plant Nigella sativa, significantly enhances immune responsiveness and suppresses pathogenicity of many viruses. . The study suggested that it blocked the replication of SARS-CoV spike (S) protein, which plays a major role in host cell viral attachment to receptor angiotensin-converting enzyme 2 (ACE2). The study reports the antinociceptive effects of thymoquinone produce via indirect activation of supraspinal $\mu 1$ - and $\kappa$ opioid receptors [57]. In reference to this hemorphins, opoid active peptide also block the effect of ACE [58]. Thus these findings suggest a similar inhibitory molecule for both opoid receptor and ACE2. Therefore, thymoquinone might be proved as a novel inhibitory molecule for ACE2 in SARS-CoV-2. In an in-Silico study [59] targeting E protein of SARs CoV-2 shows good binding affinity and confirmation ( $\mathrm{BE}=-9.01 \mathrm{kcal} / \mathrm{mol}$ ) with thymoquinone using Argus Lab 4.0. Further, their comparative study with patch dock also showed better affinity $(\mathrm{BE}=-32.03$ $\mathrm{kcal} / \mathrm{mol}$ ). Thus these findings suggest the effectiveness of thymoquinone against SARsCoV-2 targets. In the study on a natural compound having involvement in ER stress against HSPA5 substrate-binding domain $\beta$ (SBD $\beta$ ), that is known to be on recognition site of SARsCOv-2 spike show average binding energy $-6.25 \pm 1.10$ and $-5.520 \pm 0.12 \mathrm{kcal} / \mathrm{mol}$ to with thymoquinone [60]. Therefore it is probably used as an anti-covid-19 drug for the patient having pre-existing medical condition or stress. Green chiretta or Kalmegh (Andrographis paniculata) is an excellent medicinal plant having anti-HIV, anti-pathogenic, anti-viral, and immunoregulatory activities. Its bioactive constituent andrographolide has been reported to have immunoregulatory activities, plays a significant role as a modulator of altered immune responses. It can regulate both classical and alternative activation of macrophages, and specific antibody production as well as antigenspecific producing splenocytes. The insilico study [61]conducted to evaluate the potential of Andrographolide against covid-19 infection showed high binding energy, better confirmation, bioactivity, and pharmacodynamics property against main protease (Mpro) protein of SARSCoV-2. To study the potential of andrographolide (AGP1), 14-deoxy 11,12-didehydro andrographolide (AGP2), neoandrographolide (AGP3), and 14-deoxy andrographolide (AGP4), molecular dynamic and simulation study were performed against the central targets of virus namely non-structural proteins (3 L main protease (3CLpro), Papain-like proteinase (PLpro) and 
267

268

269

270

271

272

273

274

275

276

277

278

279

280

281

282

283

284

285

286

287

288

289

290

291

292

293

294

295

296

297

298 299

300

RNA-directed RNA polymerase (RdRp)) and a structural protein spike protein (S). The finding suggests the effectiveness and potential of AGP3 analog against covid-19 infection [62]. An integrated study on liquid chromatography-tandem mass spectrometry (LC-MS/MS) metabolomics and network pharmacology on kalmegh suggested its active role as immuneprotective and antiviral activity as well as its involvement in various pathway such as toll-like receptor pathway, PI3/AKT pathway, and MAP kinase pathways against SARs CoV-2 [63]. Thus, this phytochemical can inhibit viral propagation and can act as an excellent antiviral drug. Therefore, the obtained compounds if synthesized and tested on an animal model will hold promise in the treatment of the SARS CoV-2 virus.

\section{Conclusion}

The study concludes the high potential of Cinnamic acid, Thymoquinone, and Andrographolide against SARS-CoV-2 ACE2 receptor protein. The molecular docking \& molecular dynamics simulation study reveals the better binding affinity, stability, and structural conformation at the binding site of these compounds against the ACE2 receptor. Therefore, the above finding will help to design a novel potent therapeutic inhibitor against SARS-CoV-2.

\section{Acknowledgement}

We gratefully acknowledge Mr. Vinod Devaraj, Application Scientist, Schrodinger, Bangalore for his support provided in the molecular dynamics simulation study. We owe deep gratitude to the C.E.O, Biotech Park, Lucknow for their encouragement \& support in the study. The support provided by Bioinformatics tools, software's \& databases in the work is also gratefully acknowledged.

ETHICS APPROVAL AND CONSENT TO PARTICIPATE: Not applicable.

HUMAN AND ANIMAL RIGHTS: No Animals/Humans were used for studies that are the basis of this research.

CONSENT FOR PUBLICATION: Not applicable.

FUNDING: None.

CONFLICT OF INTEREST: The authors declare no conflict of interest, financial or otherwise 
1. R. Lu, X. Zhao, J. Li, P. Niu, B. Yang, H. Wu, W. Wang, H. Song, B. Huang, N. Zhu. Genomic characterization and epidemiology of 2019 novel coronavirus: implications for virus origins and receptor binding. Lancet, 395 (2020), pp. 565-574.

2. Ahmad Abu Turab Naqvi, Kisa Fatima, Taj Mohammad, Urooj Fatima, Indrakant K. Singh, Archana Singh, Shaikh Muhammad Atif, Gururao Hariprasad, Gulam Mustafa Hasan, Md. Imtiaz Hassan. Insights into SARS-CoV-2 genome, structure, evolution, pathogenesis and therapies: Structural genomics approach. Biochimica et Biophysica Acta (BBA) - Molecular Basis of Disease. Volume 1866 (10) 2020.

3. Yuan Huang, Chan Yang, Xin-Feng $\mathrm{Xu}$, Wei $\mathrm{Xu} \&$ Shu-wen Liu. Structural and functional properties of SARS-CoV-2 spike protein: potential antivirus drug development for COVID-19. Acta Pharmacol Sin 41, 1141-1149 (2020).

4. Perlman, A. R. (2016). Coronaviruses: An Overview of Their Replication and Pathogenesis Methods Mol Biol.

5. Zhong NS, Z. B. (2003). Epidemiology and cause of severe acute respiratory syndrome (SARS) in Guangdong, Peoples Republic of China, in February 2003. Lancel. 362.

6. Sarkar M, Saha S (2020) Structural insight into the role of novel SARS-CoV-2 E protein: A potential target for vaccine development and other therapeutic strategies. PLoS ONE 15(8): e0237300.

7. Chen Wang, P. W. (2020). A novel coronavirus outbreak of global health concern. The Lancet395.

8. Li W, M. M. (2003). Angiotensin-converting enzyme 2 is a functional receptor for the SARS coronavirus. Nature.

9. Huang C, L. K. (2011). Alpha coronavirus transmissible gastroenteritis virus nsp1 protein suppresses protein translation in mammalian cells and in cell-free HeLa cell extracts but not in rabbit reticulocyte lysate. Journal of virology.

10. Tanaka T, K. W. (2012). Severe acute respiratory syndrome coronavirus nspl facilitates efficient propagation in cells through a specific translational shutoff of host mRNA. . Journal of virology.

11. Cornillez-Ty CT, L. L. (2009). Severe acute respiratory syndrome coronavirus nonstructural protein2 interacts with a host protein complex involved in mitochondrial biogenesis and intracellular signaling. . Journal of virology.

12. Chatterjee A, J. M. (2009). Nuclear magnetic resonance structure shows that the severe acute respiratory syndrome coronavirus-unique domain contains a macrodomain fold. Journal of virology.

13. Frieman M, R. K. (2009). Severe acute respiratory syndrome coronavirus papain-like protease ubiquitin-like domain and catalytic domain regulate antagonism of IRF3 and NF-kappaB signaling. Journal of virology. 
14. Serrano P, J. M. (2009). Nuclear magnetic resonance structure of the nucleic acid-binding domain of severe acute respiratory syndrome coronavirus nonstructural protein 3. Journal of virology.

15. Gadlage MJ, S. J. (2010). Murine hepatitis virus nonstructural protein 4 regulates virusinduced membrane modifications and replication complex function. Journal of virology.

16. Oostra M, H. M. (2008). Topology and membrane anchoring of the coronavirus replication complex: Not all hydrophobic domains of nsp3 and nsp6 are membranespanning. Journal of virology.

17. Imbert I, G. J. (2006). A second, non-canonical RNA-dependent RNA polymerase in SARS coronavirus. EMBO J.

18. Eckerle LD, B. M. (2010). The infidelity of SARS-CoV Nsp14-exonuclease mutant virus replication is revealed by complete genome sequencing. PLoS pathogens.

19. Zust R, C.-B. L. (2011). Thiel V. Ribose 2'-O-methylation provides a molecular signature for the distinction of self and non-self mRNA dependent on the RNA sensor Mda5. Nat. Immunol.

20. Bouvet M, D. C. (2010). In vitro reconstitution of SARS-coronavirus mRNA cap methylation PLoS pathogens.

21. Decroly E, D. C.-L. (2011). Crystal structure and functional analysis of the SARScoronavirus RNA cap 2'-O-methyltransferase nsp10/nsp16 complex. PLoS pathogens.

22. Andersen, K. R. (2020). The proximal origin of SARS-CoV-2. Nature Medicine.

23. Lu, R. Z. (2020). Genomic characterisation and epidemiology of 2019 novel coronavirus: implications for virus origins and receptor binding. Lancet 395.

24. Zhu, N. Z. (2020). A Novel Coronavirus from Patients with Pneumonia in China, 2019. N EnglJMed 382.

25. Chan, J. K. (2020). Genomic characterization of the 2019 novel human-pathogenic coronavirus isolated from a patient with atypical pneumonia after visiting Wuhan. Emerg Microbes Infect 9.

26. Letko, M. M. (2020). Functional assessment of cell entry and receptor usage for SARSCoV2 and other lineage B beta coronaviruses. . Nature Microbiology 5.

27. Abdelrahman Zeinab, Li Mengyuan, Wang Xiaosheng. Comparative Review of SARSCoV-2, SARS-CoV, MERS-CoV, and Influenza A Respiratory Viruses. Frontiers in Immunology 11. 2020.

28. Li, F. (2016). Structure, function, and evolution of coronavirus spike proteins. Annu. Rev.Virol.3.

29. Simmons, G. Z. (2013). Proteolytic activation of the SARS-coronavirus spike protein: cutting enzymes at the cutting edge of antiviral research. Antiviral Res. 100.

30. Bertram, S. e. (2011). Cleavage and activation of the severe acute respiratory syndrome coronavirus spike protein by human airway trypsin-like protease. . J. Virol. 85.

31. Zhao, Y. Z. (2020). Single-cell RNA expression profiling of ACE2, the putative receptor ofWuhan2019-nCov. bioRxiv. 
32. Wrapp D, Wang N, Corbett KS, Goldsmith JA, Hsieh CL, Abiona O, Graham BS, McLellan JS. Cryo-EM structure of the 2019-nCoV spike in the prefusion conformation. Science. 2020;367:1260-3.

33. Song W, Gui M, Wang X, Xiang Y. Cryo-EM structure of the SARS coronavirus spike glycoprotein in complex with its host cell receptor ACE2. PLoS Pathog. 2018; 14:e1007236.

34. Li F, Li W, Farzan M, Harrison S. Structure of SARS coronavirus spike receptor-binding domain complexed with receptor. Science. 2005;309:1864-8.

35. Swaminathan K. Jayachandran, Muthuswamy Anusuyadevi, Mohamed Mustafa Essa, M. Walid Qoronfleh, Decoding Information On COVID - 19: Ontological Approach Towards Design Possible Therapeutics, Informatics in Medicine Unlocked, 2020.

36. Ugur Marion I, Marion A. Molecular Modelling Reveals Eight Novel Druggable Binding Sites in SARS-CoV-2's Spike Protein. ChemRxiv; 2020. DOI: 10.26434/chemrxiv.13292768.v1.

37. Chaima Mouffouk, Soumia Mouffouk, Sara Mouffouk, Leila Hambaba, Hamada Haba. Flavonols as potential antiviral drugs targeting SARS-CoV-2 proteases (3CLpro and PLpro), spike protein, RNA-dependent RNA polymerase (RdRp), and angiotensinconverting enzyme II receptor (ACE2), European Journal of Pharmacology, 2020.

38. Si-Yuan Pan, Gerhard Litscher, Si-Hua Gao, Shu-Feng Zhou, Zhi-Ling Yu, Hou-Qi Chen, Shuo-Feng Zhang, Min-Ke Tang, Jian-Ning Sun, Kam-Ming Ko, "Historical Perspective of Traditional Indigenous Medical Practices: The Current Renaissance and Conservation of Herbal Resources", Evidence-Based Complementary and Alternative Medicine, vol. 2014, Article ID 525340, 20 pages, 2014.

39. Ekor M. The growing use of herbal medicines: issues relating to adverse reactions and challenges in monitoring safety. Front Pharmacol. 2014;4:177. Published 2014 Jan 10. doi:10.3389/fphar.2013.00177.

40. Gupta SK, Anuradha SS, Nischal KKP, Seth PK. Molecular docking and simulation studies towards exploring antiviral compounds against envelope protein of Japanese encephalitis virus. Netw Model Anal Health Inform Bioinform 2013; 2(4): 231-43.

41. Waterhouse, A., Bertoni, M., Bienert, S., Studer, G., Tauriello, G., Gumienny, R., Heer, F.T., de Beer, T.A.P., Rempfer, C., Bordoli, L., Lepore, R., Schwede, T. SWISSMODEL: homology modeling of protein structures and complexes. Nucleic Acids Res. 46(W1), W296-W303 (2018).

42. Goddard TD, Huang CC, Ferrin TE. Software extensions to UCSF chimera for interactive visualization of large molecular assemblies. Structure 2005; 13(3): 473-82.

43. Spencer TJ, Biederman J, Madras BK, Dougherty DD, Bonab AA, Livni E, Meltzer PC, Martin J, Rauch S, Fischman AJ. Further evidence of dopamine transporter dysregulation in ADHD: a controlled PET imaging study using altropane. Biol Psychiatry 2007; 62:1059-61. 
44. Manoj Kumar, A. D. (2014). In silico docking studies of bioactive natural plant products as putative DHFR antagonists. Medicinal Chemistry Research.

45. Yue Y, Sun Y, Yan X, Liu J, Zhao S, Zhang J. Evaluation of the binding of per fluorinated compound to pepsin: Spectroscopic analysis and molecular docking. Chemosphere 2016; 161: 475-81.

46. Yue Y, Zhao S, Liu J, Yan X, Sun Y. Probing the binding properties of dicyandiamide with pepsin by spectroscopy and docking methods. Chemosphere 2017; 185: 1056-62.

47. Ravi, Lokesh \& Krishnan, Kannabiran. (2016). A Handbook On Protein-Ligand Docking Tool: AutoDock4. Innovare Journal of Medical Science. 4. 28-33.

48. Nakamura K, Sekine Y, Ouchi Y, Tsujii M, Yoshikawa E, Futatsubashi M, Tsuchiya KJ, Sugihara G, Iwata Y, Suzuki K, Matsuzaki H, Suda S, Sugiyama T, Takei N, Mori N. Brain serotonin and dopamine transporter bindings in adults with high-functioning autism. Arch Gen Psychiatry 2010; 67(1): 59-68.

49. Yue Y, Zhao S, Yang YS, Yan X, Liu J, Zhang J. Effects of plant extract aurantio-obtusin on pepsin structure: Spectroscopic characterization and docking simulation. J Lumin 2017; 187: 333- 9.

50. Noriaki Okimoto, Noriyuki Futatsugi, Hideyoshi Fuji, Atsushi Suenaga, Gentaro Morimoto, Ryoko Yanai, Yousuke Ohno, Tetsu Narumi, Makoto Taiji. HighPerformance Drug Discovery: Computational Screening by Combining Docking and Molecular Dynamics Simulations. PLoS Comput Biol. 2009 Oct; 5(10): e1000528. Published online 2009 Oct 9. doi: 10.1371/journal.pcbi.1000528.

51. Wright, W.C.; Chenge, J.; Wang, J.; Girvan, H.M.; Yang, L.; Chai, S.C.; Huber, A.D.; Wu, J.; Oladimeji, P.O.; Munro, A.W.; Chen, T. Clobetasol Propionate Is a HemeMediated Selective Inhibitor of Human Cytochrome P450 3A5. Journal of Medicinal Chemistry 202063 (3), 1415-1433 DOI: 10.1021/acs.jmedchem.9b02067.

52. Liu J, Yue Y, Wang J, Yan X, Liu R, Sun Y, Li X. Study of interaction between human serum albumin and three phenanthridine derivatives: Fluorescence spectroscopy and computational approach. Spectrochim Acta A Mol Biomol Spectrosc 2015; 145: 473-81.

53. Yuanyuan Yue, Qiao Dong, Yajie Zhang, Xiaoge Li, Xuyang Yan, Yahui Sun, Jianming Liu. Synthesis of imidazole derivatives and the spectral characterization of the binding properties towards human serum albumin. Spectrochim Acta A Mol Biomol Spectrosc 2016; 153: 688-703.

54. Kuba K, Imai Y, Rao S, Gao H, Guo F, Guan B, Huan Y, Yang P, Zhang Y, Deng W, Bao L, Zhang B, Liu G, Wang Z, Chappell M, Liu Y, Zheng D, Leibbrandt A, Wada T, Slutsky AS, Liu D, Qin C, Jiang C, Penninger JM (2005) A crucial role of angiotensinconverting enzyme 2 (ACE2) in SARS coronavirus-induced lung injury. Nat Med $11: 875-879$.

55. Ilkay Erdogan Orhan, F. Sezer Senol Deniz.Natural Products as Potential Leads Against Coronaviruses: Could They be Encouraging Structural Models Against SARS-CoV- 
458

459

460

461

462

463

464

465

466

467

468

469

470

471

472

473

474

475

476

477

478

479

480

481

482

483

484

485

2?.Nat Prod Bioprospect. 2020 Aug; 10(4): 171-186. Published online 2020 Jun 11. doi: $10.1007 / \mathrm{s} 13659-020-00250-4$

56. Santos et al,2020. Antivirals Against Coronaviruses: Candidate Drugs for SARS-CoV-2 Treatment?.Front. Microbiol., 13 August 2020 https://doi.org/10.3389/fmicb.2020.01818.

57. Abdel-Fattah A.M., Matsumoto K., Watanabe H. Antinociceptive effects of Nigella sativa oil and its major component, thymoquinone, in mice. Eur. J. Pharmacol. 2000;400:89-97. doi: 10.1016/s0014-2999(00)00340-x.

58. Lantz I., Glamsta E.L., Talback L., Nyberg F. Hemorphins derived from hemoglobin have an inhibitory action on angiotensin-converting enzyme activity. FEBS Lett. 1991;287:39-41. doi: 10.1016/0014-5793(91)80011-q.

59. Abdul Khader Sultan Mohideen. Molecular Docking Analysis of Phytochemical Thymoquinone as a Therapeutic Agent on SARS-Cov-2 Envelope Protein.Biointerface Research in Applied Chemistry · January 2021, Volume 11, Issue 1, 2021, 8389- 8401.

60. Abdo A. Elfiky (2020) Natural products may interfere with SARS-CoV-2 attachment to the host cell, Journal of Biomolecular Structure and Dynamics, DOI: 10.1080/07391102.2020.1761881 .

61. Enmozhi, Sukanth Kumar et al. "Andrographolide as a potential inhibitor of SARS-CoV2 main protease: an in silico approach." Journal of biomolecular structure \& dynamics, 1-7. 5 May. 2020, doi:10.1080/07391102.2020.1760136.

62. Murugan, Natarajan Arul et al. "Computational investigation on Andrographis paniculata phytochemicals to evaluate their potency against SARS-CoV-2 in comparison to known antiviral compounds in drug trials." Journal of biomolecular structure \& dynamics, 1-12. 16 Jun. 2020, doi:10.1080/07391102.2020.1777901.

63. Banerjee et al Immunoprotective potential of Ayurvedic herb Kalmegh (Andrographis paniculata) against respiratory viral infections - LC-MS/MS and network pharmacology analysis. Phytochemical Analysis. 2020;1-11. 
Table $\mathbf{1}$ (on next page)

Comparison_between_SARS-CoV,_MERS-CoV,_and_SARS-CoV-2..docx 
1 Table1. Comparison between SARS-CoV, MERS-CoV, and SARS-CoV-2.

\begin{tabular}{|l|l|l|l|}
\hline Characteristic & SARS-CoV & MERS-CoV & SARS-CoV-2 \\
\hline $\begin{array}{l}\text { Year in which the } \\
\text { first case was } \\
\text { reported }\end{array}$ & 2002 & 2012 & 2019 \\
\hline $\begin{array}{l}\text { Country/region } \\
\text { where the first case } \\
\text { was reported }\end{array}$ & China & Middle East & China \\
\hline $\begin{array}{l}\text { The primary mode of } \\
\text { transmission }\end{array}$ & $\begin{array}{l}\text { Droplets, aerosol, and } \\
\text { contact }\end{array}$ & $\begin{array}{l}\text { Droplets, aerosol, and } \\
\text { contact }\end{array}$ & $\begin{array}{l}\text { Droplets, aerosol, and } \\
\text { contact }\end{array}$ \\
\hline Incubation period & $2-7$ days & $2-14$ days & $2-14$ days \\
\hline Host receptor & ACE2 & DPP4 & ACE2 \\
\hline Case fatality rate & Approximately 15\% & $34.4 \%$ & $1-3 \%$ \\
\hline
\end{tabular}

2 
Table 2 (on next page)

List_of_natural_Compound.docx 
1 Table2. List of natural compounds and their chemical properties used for study.

\begin{tabular}{|c|c|c|c|c|c|}
\hline S.No. & Compound Name & Plant derived & $\begin{array}{l}\text { Mol. } \\
\text { wt(g/mol) }\end{array}$ & $\begin{array}{l}\text { H-bond } \\
\text { donor }\end{array}$ & $\begin{array}{l}\text { H-bond } \\
\text { Acceptor }\end{array}$ \\
\hline 1. & Choline & $\begin{array}{l}\text { Withania } \\
\text { Somnifera }\end{array}$ & 104.17 & 1 & 2 \\
\hline 2. & Harmine & $\begin{array}{l}\text { Passiflora } \\
\text { Incarnata }\end{array}$ & 182.23 & 1 & 2 \\
\hline 3. & Cinnamaldehyde & $\begin{array}{l}\text { Cinnamonum } \\
\text { Cassia }\end{array}$ & 132.16 & 0 & 1 \\
\hline 4. & Cinnamic Acid & Bromeliad & 148.16 & 1 & 2 \\
\hline 5. & Coumarins & $\begin{array}{l}\text { Dypsis } \\
\text { Lutescens }\end{array}$ & 146.15 & 0 & 2 \\
\hline 6. & Ursolic Acid & $\begin{array}{l}\text { Ocimum } \\
\text { Basilicum }\end{array}$ & 456.7 & 2 & 3 \\
\hline 7. & Chlorogenic Acid & Daucus Carota & 354.31 & 6 & 9 \\
\hline 8. & Assafoetidnol B & $\begin{array}{l}\text { Ferula } \\
\text { Assafoetida }\end{array}$ & 456.54 & 2 & 7 \\
\hline 9. & Glucobrassicin & $\begin{array}{l}\text { Brassica } \\
\text { Oleracea }\end{array}$ & 448.48 & 6 & 11 \\
\hline 10. & Linamarin & $\begin{array}{l}\text { Phaseolus } \\
\text { Lunatus }\end{array}$ & 247.25 & 4 & 7 \\
\hline 11. & Luteolin & $\begin{array}{l}\text { Thymus } \\
\text { Vulgaris }\end{array}$ & 286.24 & 4 & 6 \\
\hline 12. & Andrographolide(Kalmegh) & $\begin{array}{l}\text { Andrographis } \\
\text { Paniculata }\end{array}$ & 350.4 & 3 & 5 \\
\hline 13. & Catechin & $\begin{array}{l}\text { Camellia } \\
\text { Sinensis }\end{array}$ & 458.4 & 15 & 12 \\
\hline 14. & Citral & $\begin{array}{l}\text { Melissa } \\
\text { Officinalis }\end{array}$ & 152.24 & 0 & 1 \\
\hline 15. & Hydroxychloroquine & Synthetic & 335.9 & 2 & 4 \\
\hline 16. & Linalool & $\begin{array}{l}\text { Lavandula } \\
\text { Angustifolia }\end{array}$ & 154.25 & 1 & 1 \\
\hline 17. & Nicotine & $\begin{array}{l}\text { Nicotiana } \\
\text { Tabocum }\end{array}$ & 162.23 & 0 & 2 \\
\hline 18. & Chloroquine & $\begin{array}{l}\text { Helianthus } \\
\text { Annus }\end{array}$ & 319.9 & 1 & 3 \\
\hline 19. & Allium & Allium Sativum & 150.3 & 0 & 0 \\
\hline 20. & Thymoquinone & Nigella Sativa & 164.2 & 0 & 2 \\
\hline
\end{tabular}


Table 3 (on next page)

List_of_synthetic_compounds.docx 
1 Table3. List of synthetic compounds and their chemical properties used for study.

\begin{tabular}{|l|l|l|l|l|}
\hline S.No. & Compound Name & Mol. wt (g/mol) & H-bond donor & H-bond Acceptor \\
\hline $\mathbf{1 .}$ & Amprenavir & 505.64 & 1 & 4 \\
\hline 2. & Acyclovir & 225.21 & 4 & 8 \\
\hline 3. & Umifenovir & 477.42 & 1 & 5 \\
\hline 4. & Combivir & 505.5 & 5 & 18 \\
\hline $\mathbf{5 .}$ & Tamiflu & 312.41 & 3 & 6 \\
\hline 6. & Zanamivir & 332.31 & 9 & 11 \\
\hline 7. & Cidofovir & 279.19 & 5 & 9 \\
\hline 8. & Peramivir & 328.41 & 7 & 8 \\
\hline
\end{tabular}

2 
Table 4 (on next page)

Molecular_docking_result.docx 
1 Table4. Result of molecular docking study with natural and synthetic compounds

\begin{tabular}{|c|c|c|}
\hline S.No. & Compound Name & Binding Energy ( Kcal/Mol) \\
\hline 1. & Choline & -3.99 Kcal/Mol \\
\hline 2. & Harmine & -3.71 Kcal/Mol \\
\hline 3. & Cuminaldehyde & $-4.00 \mathrm{Kcal} / \mathrm{Mol}$ \\
\hline 4. & Cinnamic Acid & $-5.20 \mathrm{Kcal} / \mathrm{Mol}$ \\
\hline 5. & Curcumrin & $-2.42 \mathrm{Kcal} / \mathrm{Mol}$ \\
\hline 6. & Ursolic Acid & -3.43 Kcal/Mol \\
\hline 7. & Chlorogenic Acid & $-4.20 \mathrm{Kcal} / \mathrm{Mol}$ \\
\hline 8. & Assafoetidnol B & -3.82 Kcal/Mol \\
\hline 9. & Glucobrassicin & -3.65 Kcal/Mol \\
\hline 10. & Linamarin & -2.32 Kcal/Mol \\
\hline 11. & Luteolin & $-4.19 \mathrm{Kcal} / \mathrm{Mol}$ \\
\hline 12. & Amprenavir & $-0.84 \mathrm{Kcal} / \mathrm{Mol}$ \\
\hline 13. & Acyclovir & -3.24 Kcal/Mol \\
\hline 14. & Umifenovir & $-2.30 \mathrm{Kcal} / \mathrm{Mol}$ \\
\hline 15. & Combivir & $-1.23 \mathrm{Kcal} / \mathrm{Mol}$ \\
\hline 16. & Tamiflu & -3.14 Kcal/Mol \\
\hline 17. & Zanamivir & -2.00 Kcal/Mol \\
\hline 18. & Thymoquinone & $-4.71 \mathrm{Kcal} / \mathrm{Mol}$ \\
\hline 19. & Cidofovir & $-1.78 \mathrm{Kcal} / \mathrm{Mol}$ \\
\hline 20. & Peramivir & -3.84 Kcal/Mol \\
\hline 21. & Andrographolide(Kalmegh) & $-4.63 \mathrm{Kcal} / \mathrm{Mol}$ \\
\hline 22. & Greentea & -3.25 Kcal/Mol \\
\hline 23. & Citral & -2.82 Kcal/Mol \\
\hline 24. & Hydroxychloroquine & -2.70 Kcal/Mol \\
\hline 25. & Linalool & +1.49 Kcal/Mol \\
\hline 26. & Nicotine & -1.27 Kcal/Mol \\
\hline 27. & Chloroquine & $-2.52 \mathrm{Kcal} / \mathrm{Mol}$ \\
\hline 28. & Allium & + $0.58 \mathrm{Kcal} / \mathrm{Mol}$ \\
\hline
\end{tabular}

2 
Table 5 (on next page)

Best_Five_Docking_Result. 
1 Table5. Result of top five best docking score with H-bond interaction.

\begin{tabular}{|l|l|l|l|}
\hline S.No. & Compound Name & $\begin{array}{l}\text { Binding Energy } \\
(\text { Kcal/Mol) }\end{array}$ & \multicolumn{1}{|c|}{ H-Bond Interaction } \\
\hline $\mathbf{1 .}$ & Cinnamic acid & $-5.20 \mathrm{kcal} / \mathrm{Mol}$ & ALA-264,LYS-481, LEU-503 \\
\hline $\mathbf{2 .}$ & Thymoquinone & $-4.71 \mathrm{kcal} / \mathrm{Mol}$ & LEU-103, TRP-165, ARG-169 \\
\hline $\mathbf{3 .}$ & Andrographolide(Kalmegh) & $-4.63 \mathrm{Kcal} / \mathrm{Mol}$ & $\begin{array}{l}\text { ARG-273, TYR-127, ASN- } \\
277, \text { ASN-277 }\end{array}$ \\
\hline $\mathbf{4 .}$ & Cholengenic acid & $-4.20 \mathrm{kcal} / \mathrm{Mol}$ & ARG-273, ARG-273 \\
\hline $\mathbf{5 .}$ & Cuminaldehyde & $-4.00 \mathrm{Kcal} / \mathrm{Mol}$ & TRP-165 \\
\hline
\end{tabular}

2 
Figure 1

Fig1._Protein_modeled_structure_.jpg

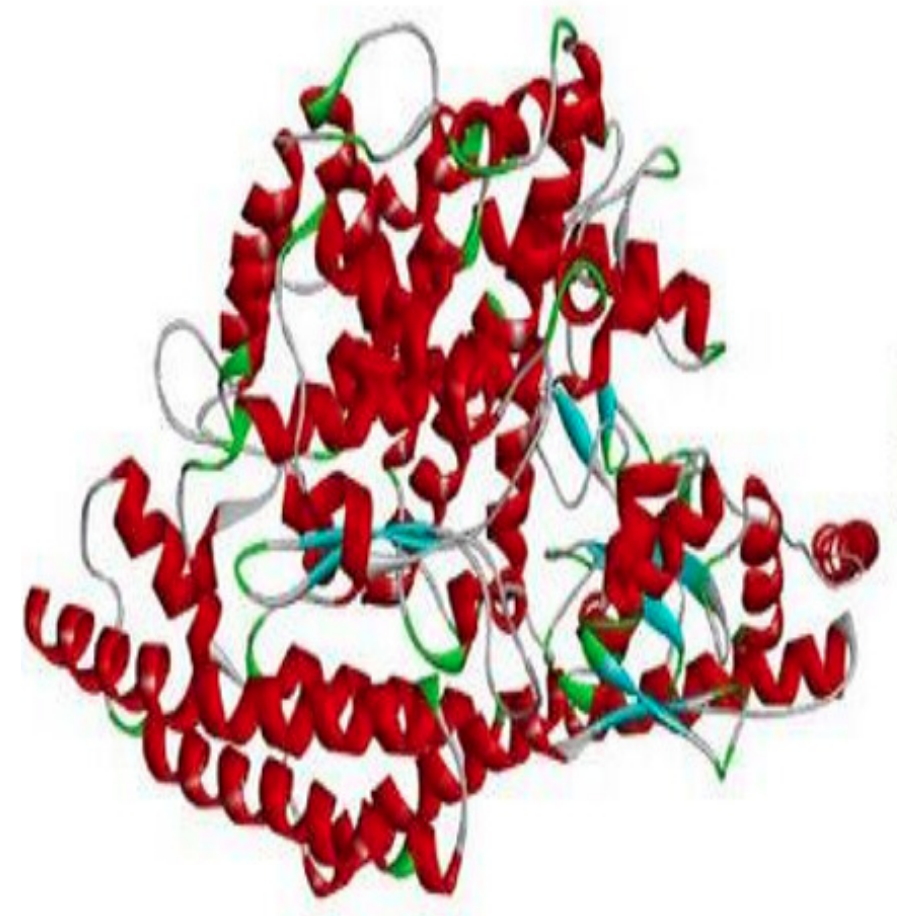

(A)

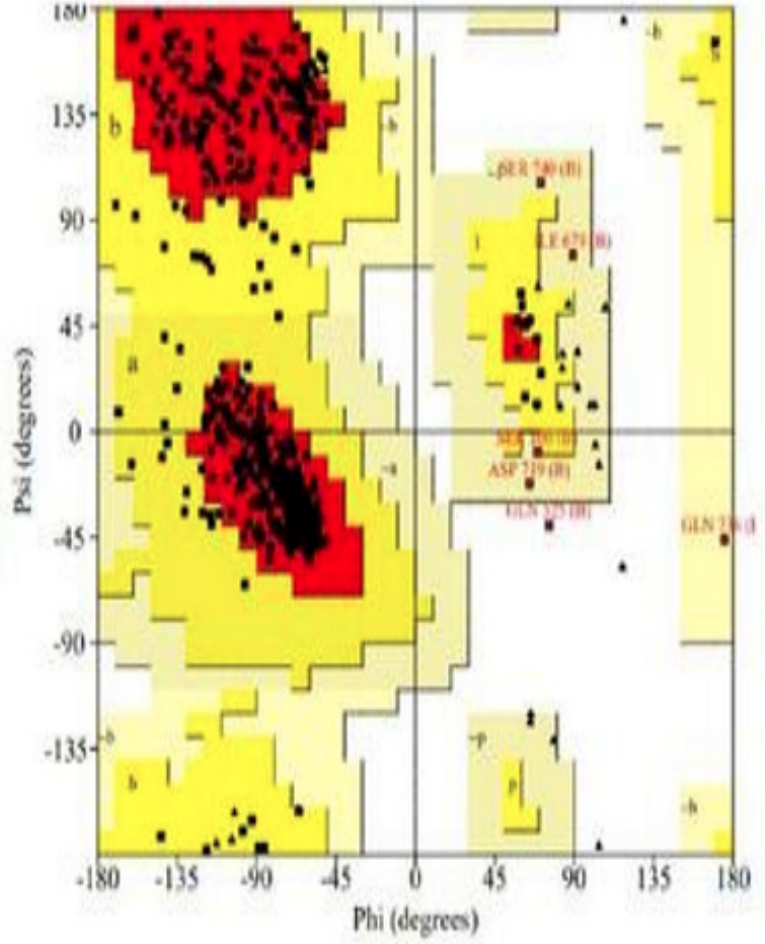

(B)

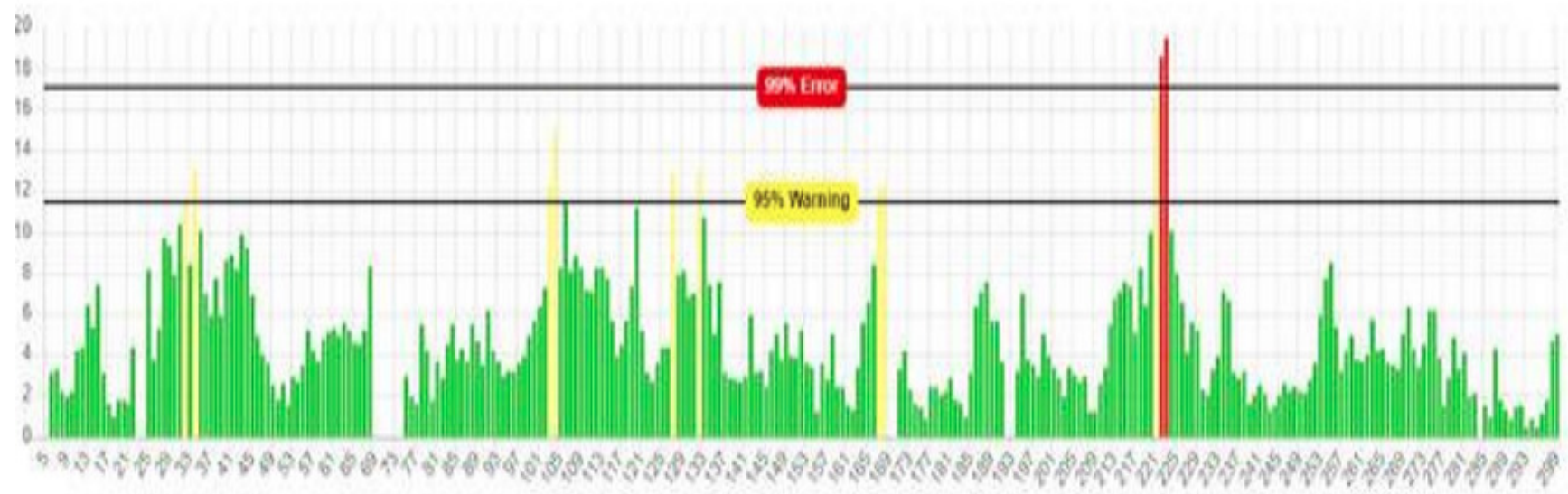

(C) 
Figure 2

molecular_dynamic_simulation_of_ACE2-Cinnamic_acid.png

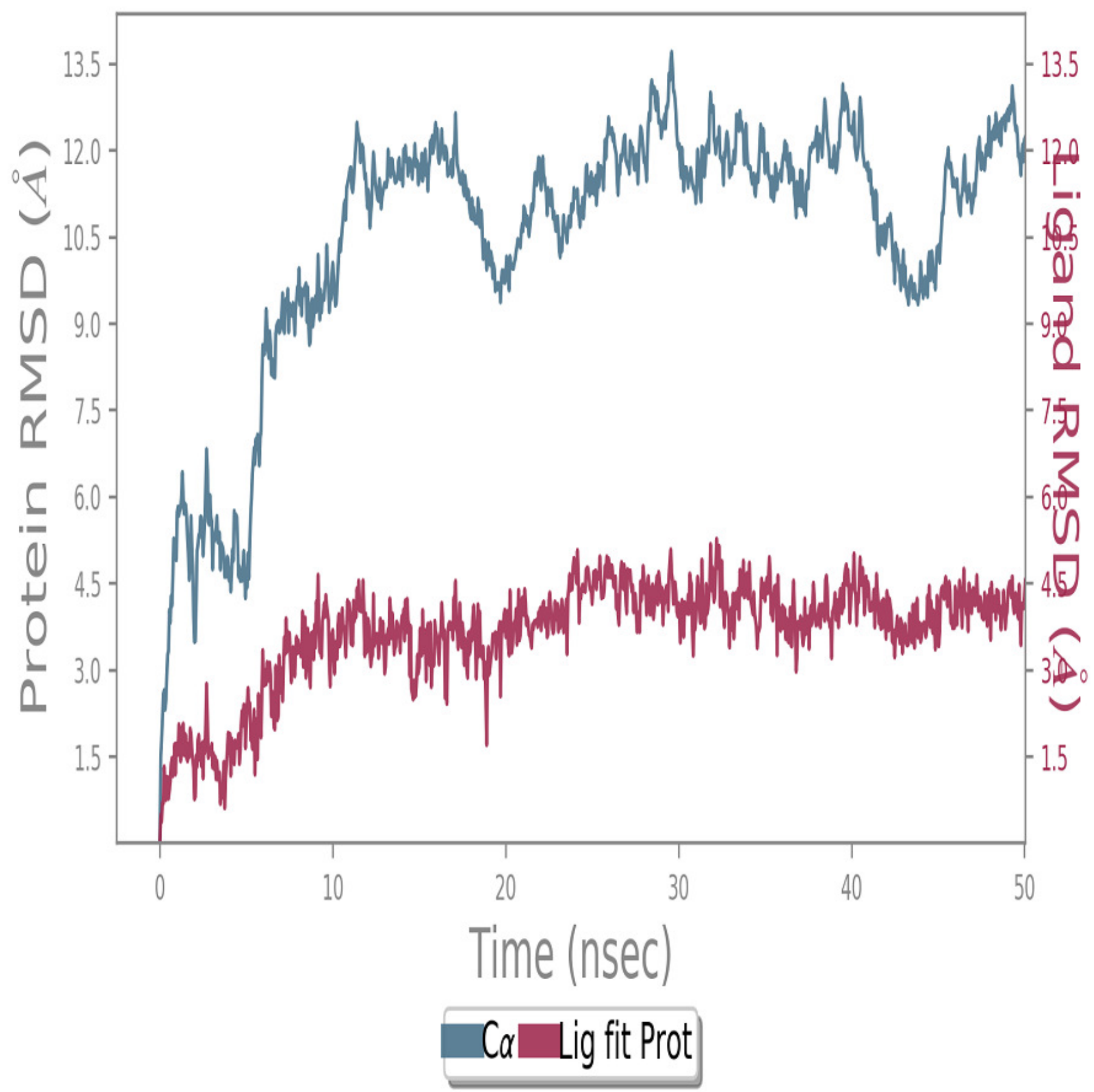


Figure 3

Fig2.Molecular_interaction_study.jpg

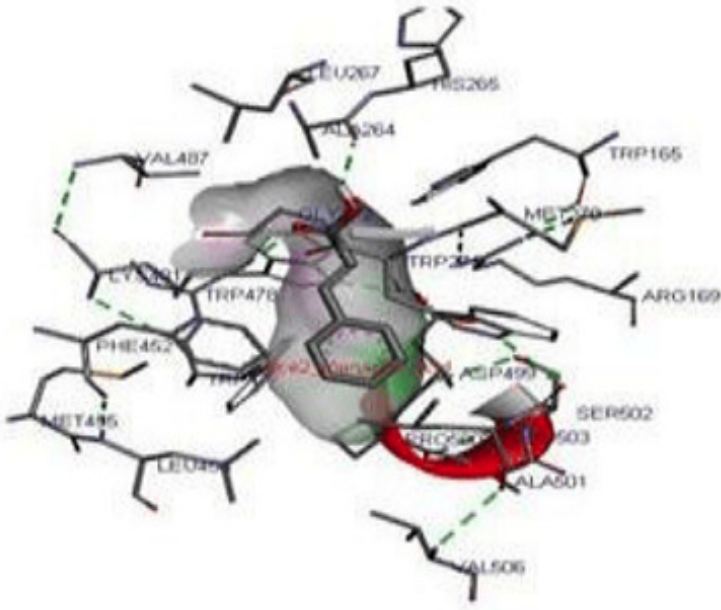

(A)

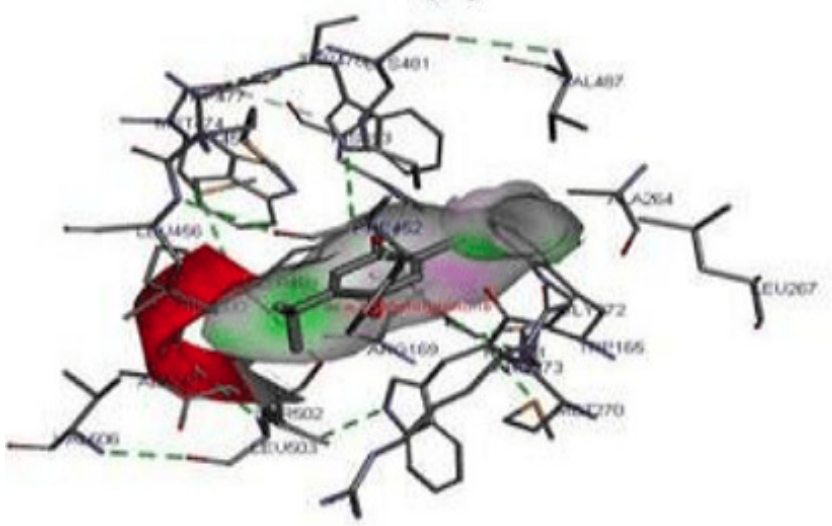

(C)

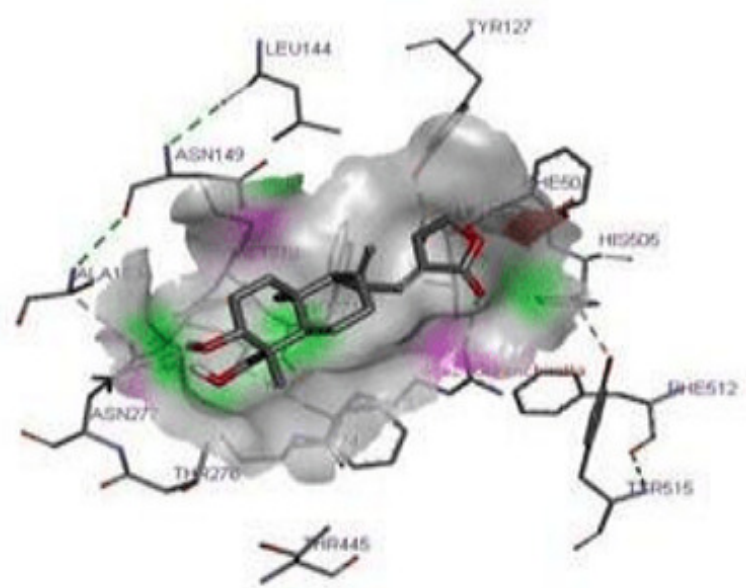

(B)

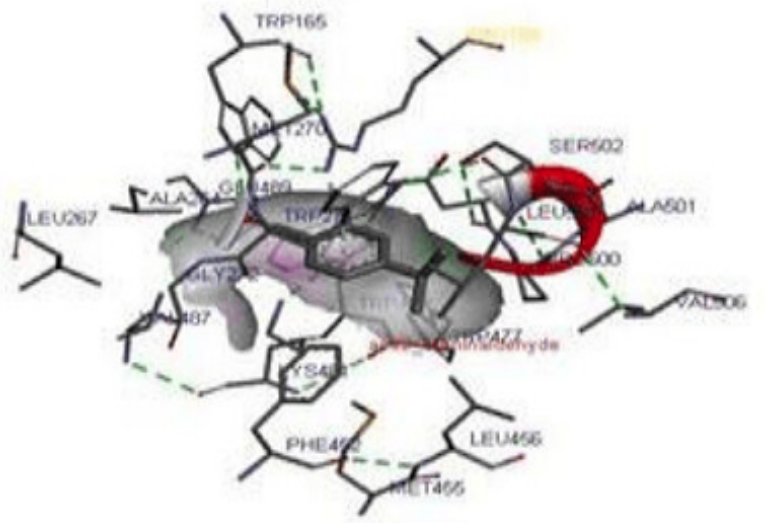

(D)

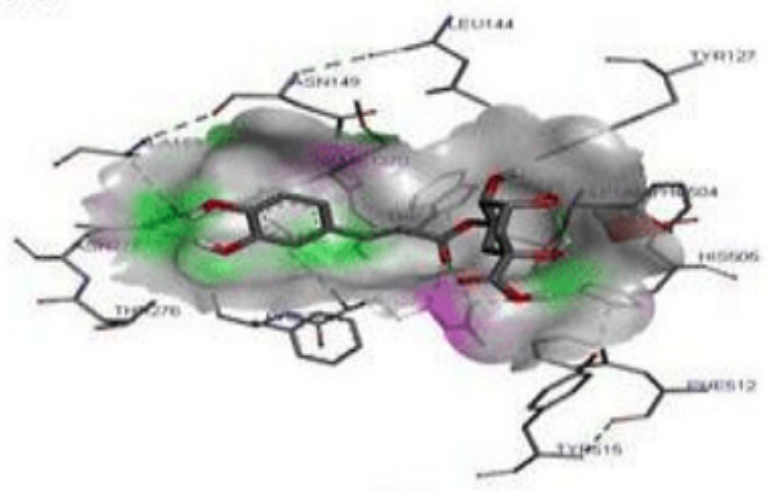

(E) 
Figure 4

Fig4._Molecular_dynamic_simulation_study_of_ACE2-Thymoquinone.png

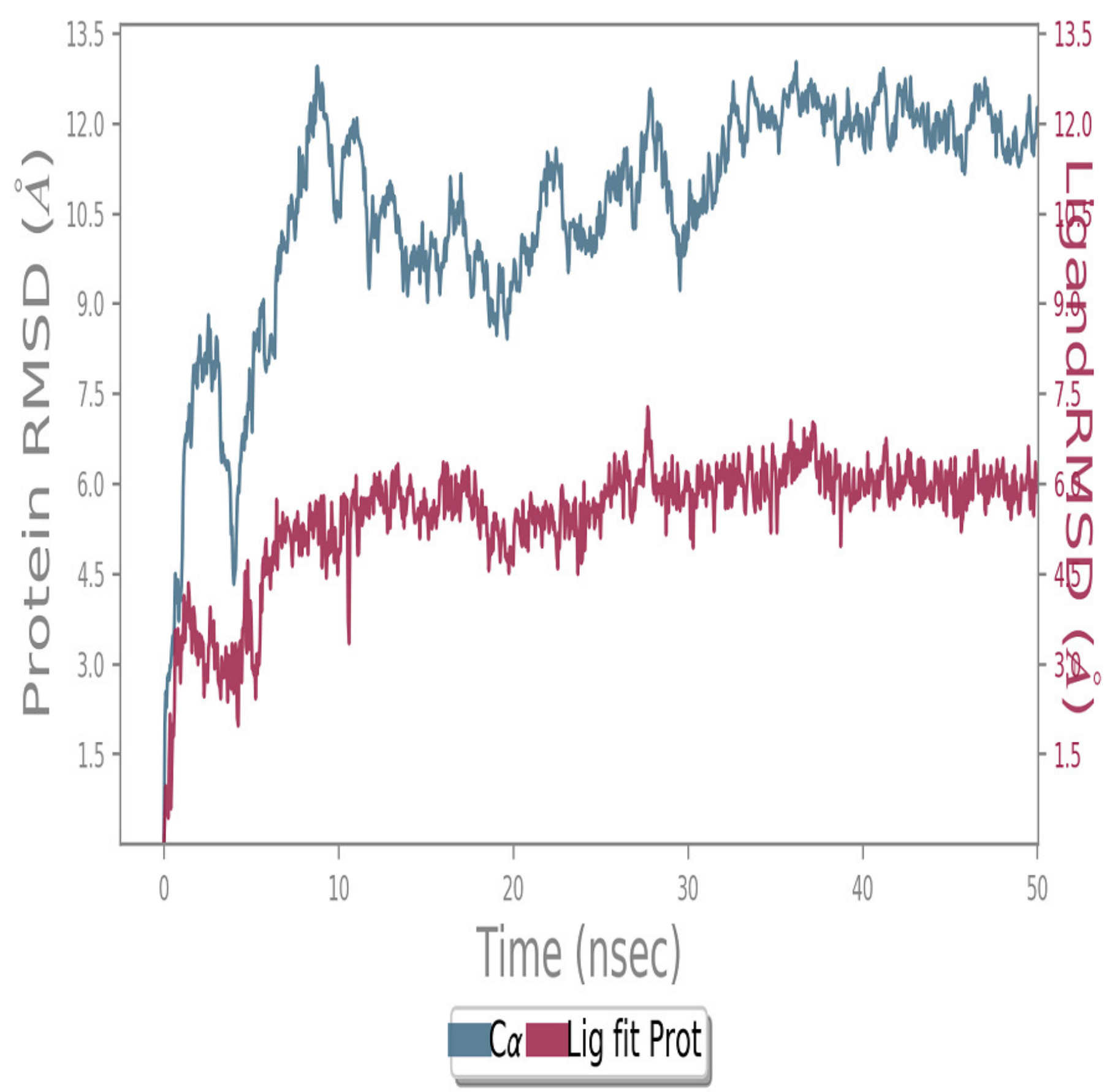


Figure 5

Molecular_dynamic_simulation_study_of_ACE2-Andrographolide_png

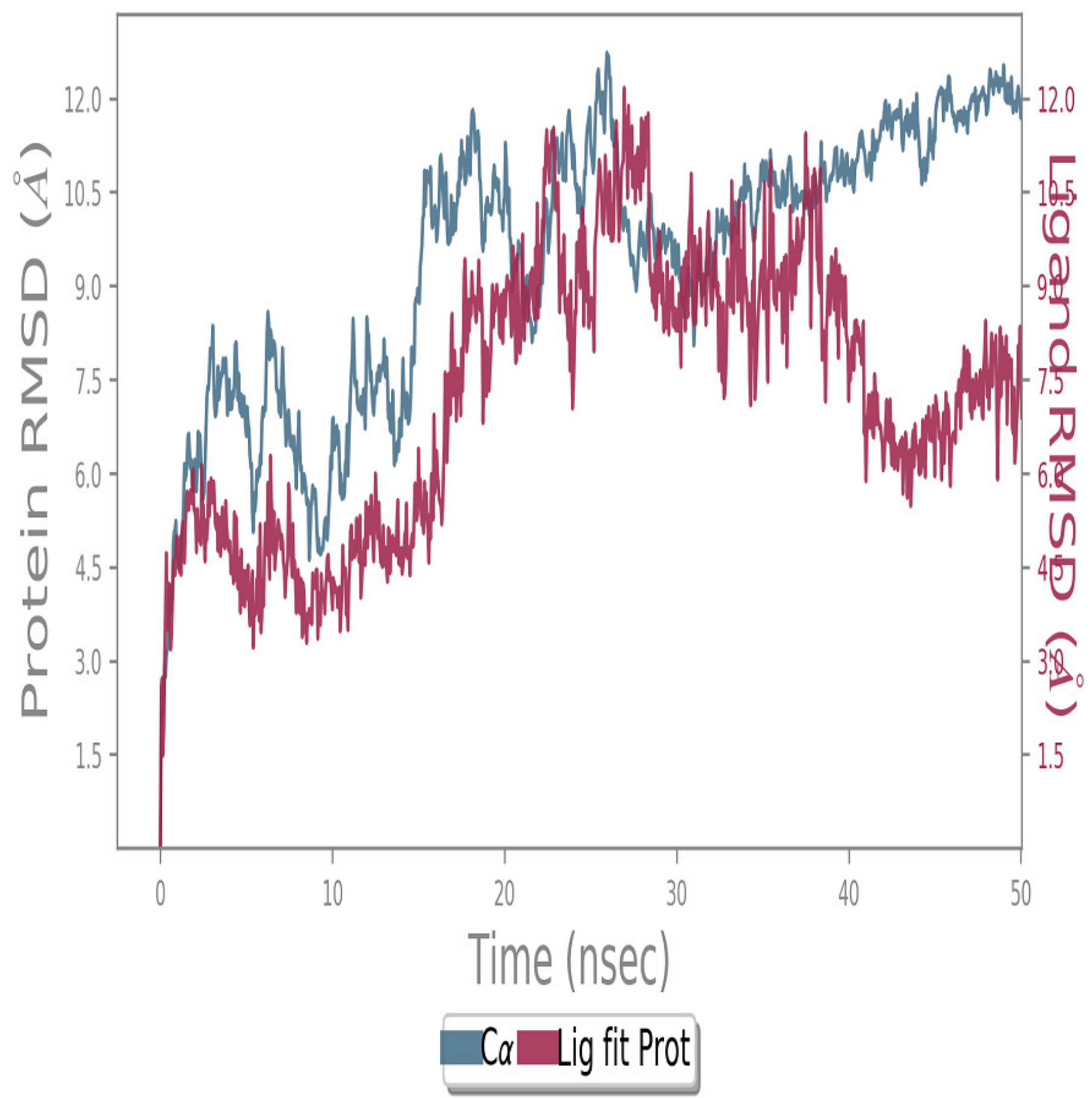

